\title{
Abomasal nematodes of sheep and goats slaughtered in Awassa (Ethiopia): species composition, prevalence and vulvar morphology
}

\author{
N. THOMAS, S. TESHALE, B. KUMSA*
}

Department of Veterinary Parasitology, Faculty of Veterinary Medicine, Addis Ababa University P.O. Box 34, Debre

Zeit, Ethiopia, E-mail: bersissak@yahoo.com

\begin{abstract}
Summary
A study was carried out to determine the prevalence of abomasal nematodes of sheep and goats slaughtered in Awassa town from January 2006 through June 2006 with special emphasis given to Haemonchus spp. and to characterize vulvar morphs of female Haemonchus worms. During the study period 180 abomasa of sheep and 132 abomasa of goats were examined. Three genera of nematodes were identified in both sheep and goats abomasa with overall prevalence of $91.1 \%$ and $87.1 \%$ respectively. The specific prevalence rates observed were $81.1 \%$ for Haemonchus spp., $47.2 \%$ for Trichostrongylus axei, and $19.4 \%$ for Teladorsagia spp. in sheep and $76.5 \%$ for Haemonchus spp., $39.4 \%$ for $T$. axei and $20.5 \%$ for Teladorsagia spp. in goats. Out of 653 female Haemonchus recovered from sheep, $37.8 \%$ had a linguiform vulvar flap, $30 \%$ knobbed and $35.4 \%$ smooth vulvar morphs. Out of 448 female Haemonchus recovered from goats, $43.8 \%$ had linguiform vulvar flaps, $27.2 \%$ knobbed and $29 \%$ smooth morph type. A total of 239 linguiform female Haemonchus from sheep were further classified in to $15.1 \%$ linguiform A (LA), $17.5 \%$ linguiform B (LB), $39.7 \%$ linguiform C (LC) and $27.6 \%$ linguiform I (LI) and similarly from goats 196 linguiform female Haemonchus were further classified into $11.2 \% \mathrm{LA}, 12.2 \% \mathrm{LB}, 44.9 \% \mathrm{LC}$ and $31.6 \% \mathrm{LI}$. Similar findings were observed in both host species regarding the worm burden, prevalence of infection and morphological pattern of Haemonchus species. Generally a high infection rate with abomasal nematodes was observed in both sheep and goats of the study area.
\end{abstract}

Key words: abomasal nematodes; Awassa; Haemonchus; Teladorsagia; Trichostrongylus axei; prevalence; vulvar flap

\section{Introduction}

Ethiopia, with its great variation in climate and topogra- phy, possesses one of the largest small ruminant populations in Africa. The latest estimate of small ruminant population gives 23.6 million sheep and 23.3 million goats (CSA, 2004). Small ruminants play a significant role in maintaining household stability by providing meat, milk, skin and wool, generate cash income and play traditional social and religious roles (Devendera \& Mclery, 1982; ElAzazy, 1995). Studies have revealed that ruminants contribute $80 \%$ of the total food production from livestock in tropical Africa, of which small ruminants account for about $22 \%$.

However, in spite of the presence of huge numbers of small ruminant populations, Ethiopia fails optimally to exploit these resources. This is due to a multitude of constraining factors like ill health (Bekele et al., 1982; Teklye et al., 1987). Health disorders in all classes of small ruminants represent the major problems and greatly affect the economics of sheep and goat production. Gastrointestinal helminthosis is among the main constraints to small ruminant productions in Ethiopia. These parasites pose subtle economic losses and are the major factors responsible for lowered levels of production in many parts of the country. Abomasal nematodes and liver flukes are believed to be the most prevalent and widely distributed helminths (Barger, 1982).

Even though the losses incurred by these parasites are believed to be significant, accurate and up-to-date estimates of the economic impacts are lacking in Ethiopia. Available information revealed that infection due to abomasal nematodes especially $H$. contortus is responsible for important morbidities and mortalities in sheep and goats in different parts of the country (Bekele et al., 1982; Teklye et al., 1987). Mulugeta et al. (1989) reported yearly losses amounting to USD 82 million due to endoparasites in Ethiopia. Krecek and Waller (2006) reported that H. contortus alone is responsible for annual loss ranging from

* Corresponding author 
USD 26 million to 45 million in Kenya and South Africa. Studies conducted on gastrointestinal helminthosis of small ruminants (Abebe \& Esayas, 2001; Bekele et al., 1982; Donald, 1999) indicated the importance of nematodes as a cause of impaired productivity. However, nationwide studies have never been carried out to determine the distribution of abomasal nematodes. Most previous studies in Ethiopia were based on coprological examinations, which are less sensitive in identifying the nematode species. We conducted this study to identify the species and determine the prevalence of abomasal nematodes of sheep and goats in and around Awassa town.

\section{Materials and Methods}

\section{Study area}

The study was conducted in Awassa town, the capital of Sidama zone, which is located in the northern part of Southern Nations, Nationalities and People's Region (SNN PR) $275 \mathrm{~km}$ south of Addis Ababa, capital of Ethiopia. Geographically the area lies between $4^{\circ} 27^{\prime}$ and $80^{\circ} 30^{\prime} \mathrm{N}$ latitude and $34^{\circ} 21^{\prime}$ and $39^{\circ} 11^{\prime}$ E longitude (Fig. 1). During the study period, Awassa received an annual average rainfall ranging from 801 to $1000 \mathrm{~mm}$ and with a mean temperature of the area of $20.1-25^{\circ} \mathrm{C}$ with an average altitude of $1790 \mathrm{~m}$ above sea level. The area is mainly covered by dry savanna and bush types of vegetation.

\section{Study animals and design}

The study was conducted on sheep and goats slaughtered in different restaurants in Awassa town. Most of the study animals were originated from Awassa and different areas of Sidama zone. As most of these animals were obtained from different markets it is difficult to trace the exact locality of their origin. Regular visits to restaurants in Awassa town allowed collections of abomasa of sheep and goats for the study. As soon as possible, after removal of the alimentary tract from the body cavity, the abomasa ligated at both ends were cut and transported to the parasitology laboratory of Animal Science Department of Awassa College of Agriculture for microscopic examination.

\section{Worm recovery, identification and count}

Worm recovery, species identification and determination of worm burden were carried out according to standard procedures described by Hansen and Perry (1994) and MAFF (1977). The abomasa were ligated at both ends and removed from omasum and duodenum. Then they were opened along the greater curvature and their contents were thoroughly washed in to a graduated bucket under a slow jet of water (the approximate volume of the abomasal content was 0.751$)$. The mucus membrane was carefully rubbed with fingers to remove any worms adhering to it. The contents and washings were made to a total volume of two liters. Then it was vigorously stirred until all the abomasal contents, mucous and water were thoroughly mixed. A total of $200 \mathrm{ml}$ of the contents was then transferred to measuring cylinder in five steps of $40 \mathrm{ml}$ per step while stirring the mixture. A sub-sample of $20 \mathrm{ml}$ was transferred to a small graduated beaker to which $2-3 \mathrm{ml}$ iodine was added to stain the worm and $2-3 \mathrm{ml}$ sodium thiosulfate solution was also added to decolorize debris. Finally about $3-4 \mathrm{ml}$ of the sample was placed in a Petri dish having parallel lines marked at $5 \mathrm{~mm}$ apart, diluted with water and examined under a stereomicroscope. Samples were examined for the presence of nematodes, which were identified and counted as male or female. The total number of worms counted in the $20 \mathrm{ml}$ sub-sample was then multiplied by 100 to get the total number of worms present in the abomasum.

\section{Vulvar morphology of Haemonchus species}

A representative number of female worms collected from each host species were classified according to their vulvar morphology under a stereomicroscope as follows: Linguiform females (with a supra vulvar flap), knobbed females (with knob like vulvar process) and smooth females (with out any vulval process). Identification was performed according to the criteria set by Rose (1966) and Jacquiest et al. (1995).

Each linguiform female Haemonchus worms were further classified in to sub linguiform types (A, B, C \& I) as has been described by Le Jamber and WhitLock (1968). Linguiform $\mathrm{A}$ has one cuticular inflation, Linguiform $\mathrm{B}$ has no cuticular inflations, Linguiform $\mathrm{C}$ has two cuticular inflations while in Linguiform I, the cuticular inflation arises from the linguiform process.

\section{Statistical analysis}

Descriptive statistics were used to summarize the data. In addition, Microsoft Excel software was used to store the

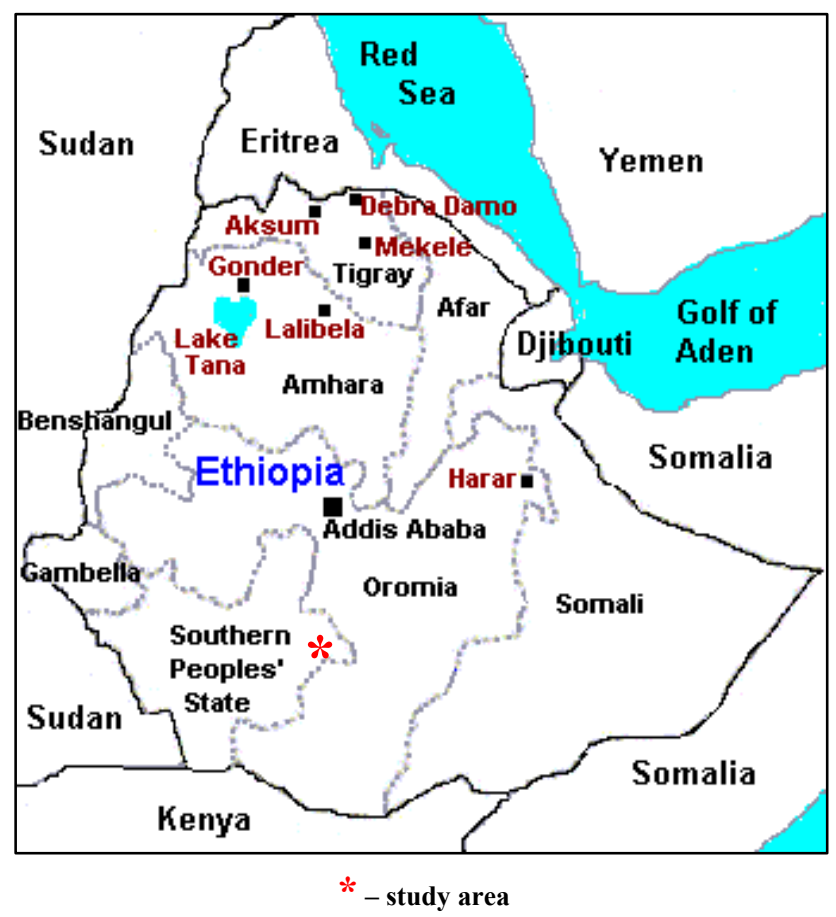

Fig. 1. Map of Ethiopia showing the location of the study area 
data of abomasal nematodes. The software program, Stata, (intercooled Stata 7.5) and SPSS 11.5 were employed for data analysis.

\section{Results}

Prevalence and worm burden of abomasal nematodes Examination of 180 abomasa of sheep revealed the presence of three different genera of nematodes with overall prevalence rates of $91.1 \%(\mathrm{n}=164)$. The different genera identified were: Haemonchus $81.1 \%$, T. axei $47.2 \%$ and Teladorsagia $19.4 \%$ (Table 1). Likewise, of the total 132 abomasa of goats examined three genera of nematodes with overall prevalence rate of $87.1 \%(n=115)$ were recorded. The three genera of nematodes identified were: Haemonchus $76.5 \%$, T. axei $39.4 \%$ and Teladorsagia $20.5 \%$ (Table 2).

The overall monthly average worm burden ranged from 1690.1 in January to 2344.3 in March for sheep whereas it varied from 1601.1 in May to 2165.2 in January for goats. In sheep the highest Haemonchus count was recoded in April (726.9) and the lowest in February (578.3) and falls between these values for other months as shown in Table 1. The highest $T$. axei burden was recorded in March (942.1) and the lowest in January (500), while for Teladorsagia the highest worm burden was found in March (742.8) while the lowest was observed in February (400). In goats the average worm count for Haemonchus spp. was highest in January (670) and lowest in April (514.3), for T. axei the highest count was recorded in January (920) and lowest in May (453.3), where as the highest count for Teladorsagia was observed in January (575.2) and the lowest in June (500) as shown in Table 2. Generally sheep with 1903.1 overall mean worm count were found to be more heavily infested than goats with 1832.5 overall mean worm count during the study period. However, there was no statistically significant $(\mathrm{P}>0.05)$ difference between months and host species in prevalence and worm burden of abomasal nematodes.

Vulvar morphology of Haemonchus species

Out of the total 653 female Haemonchus worms from sheep abomasa subjected to the vulvar morphology study, $37.8 \%$ linguiform, $35.4 \%$ smooth and $30 \%$ knobbed vulval morphs were identified (Table 4). Similarly from the abomasa of goats, 448 female Haemonchus were categoryzed into $43.8 \%$ linguiform, $29 \%$ smooth and $27.2 \%$ knobbed vulvar morphs. There was no significant $(\mathrm{P}>0.05)$ difference in the proportion of the different vulvar morphs between sheep and goats. In both sheep and goat hosts, the linguiform type was encountered as the most predominant type of vulvar morphology. The study also showed that there was insignificant $(\mathrm{P}>0.05)$ variation in the proportion of the major vulvar morph types in different months in both sheep and goats.

A total of 239 linguiform female Haemonchus worms from

Table 1 . Monthly prevalence and mean count of abomasal nematodes in sheep

\begin{tabular}{lccccc}
\hline Month & No. examined & $\begin{array}{c}\text { Haemonchus spp. } \\
(\%)\end{array}$ & $\begin{array}{c}\text { T. axei } \\
(\%)\end{array}$ & $\begin{array}{c}\text { Teladorsagia spp. } \\
(\%)\end{array}$ & Total \\
\hline January & 20 & $85(623.5)$ & $55(500)$ & $15(566.6)$ & 1690.1 \\
February & 30 & $76.6(578.3)$ & $46.6(792.8)$ & $16.6(400)$ & 1771.1 \\
March & 40 & $77.5(659.4)$ & $47.5(942.1)$ & $17.5(742.8)$ & 2344.3 \\
April & 32 & $81.3(726.9)$ & $34.4(818.1)$ & $12.5(625)$ & 2170 \\
May & 30 & $83.3(632)$ & $46.6(733.3)$ & $26.6(587.5)$ & 1952.8 \\
June & 28 & $85.5(617.4)$ & $53.5(820)$ & $28.5(562.5)$ & 1999.9 \\
Total & 180 & $81.1(639.6)$ & $47.2(767.8)$ & $19.4(495.7)$ & 1903.1 \\
\hline
\end{tabular}

$\mathrm{P}>0.05$ for monthly prevalence and total worm burden; Values in bracket are the mean worm burden

Table 2. Monthly prevalence and mean count of abomasal nematodes in goats

\begin{tabular}{lccccc}
\hline Month & No. examined & $\begin{array}{c}\text { Haemonchus } \text { spp. } \\
(\%)\end{array}$ & $\begin{array}{c}\text { T. axei } \\
(\%)\end{array}$ & $\begin{array}{c}\text { Teladorsagia spp. } \\
(\%)\end{array}$ & Total \\
\hline January & 14 & $71.4(670)$ & $42.9(920)$ & $23.7(510.5)$ & 2165.2 \\
February & 38 & $76.3(640)$ & $44.7(706)$. & $16.6(400)$ & 1846.7 \\
March & $\mathrm{ND}$ & $\mathrm{ND}$ & $\mathrm{ND}$ & $\mathrm{ND}$ & $\mathrm{ND}$ \\
April & 20 & $70(514.3)$ & $40(612.5)$ & $20(575)$ & 1701.8 \\
May & 40 & $77.5(580.6)$ & $32.5(453.8)$ & $15(566.7)$ & 1601.1 \\
June & 20 & $85(658.8)$ & $45(688.8)$ & $20(500)$ & 1847.6 \\
Total & 132 & $76.5(612.7)$ & $39.4(673.3)$ & $20.5(543.5)$ & 1832.5 \\
\hline
\end{tabular}

$\mathrm{P}>0.05$ for monthly prevalence and total worm burden; Values in bracket are mean worm burden; ND - Not Done 
Table 3. Monthly percentage of vulvar morph types of Haemonchus spp. in sheep and goats.

\begin{tabular}{llccccccc}
\hline $\begin{array}{l}\text { Host spp } \\
\text { and worm no }\end{array}$ & Vulvar morphology & Jan. & Feb. & Mar. & Apr. & May & June & Average \\
\hline Sheep & Linguiform (\%) & 38.3 & 24.2 & 41.2 & 40.1 & 35.9 & 41.3 & 37.8 \\
(N=653) & Knobbed (\%) & 26 & 40.6 & 18.1 & 25.9 & 42.7 & 27.9 & 30 \\
& Smooth (\%) & 35.6 & 34.9 & 35.5 & 33.8 & 21.4 & 28.2 & 35.4 \\
Goats & Linguiform (\%) & 44.2 & 44.3 & ND & 44.6 & 42.6 & 43.56 & 43.8 \\
$(\mathrm{n}=448)$ & Knobbed (\%) & 23.3 & 29.1 & ND & 29.8 & 26.2 & 25.1 & 27.2 \\
& Smooth (\%) & 32.5 & 26.5 & ND & 25.5 & 31.1 & 25.6 & 29 \\
\hline ND- Not Don & & & & & & & &
\end{tabular}

ND - Not Done

Table 4. Monthly percentage of the different linguiform morphotypes of Haemonchus spp. in sheep and goats

\begin{tabular}{lcccccccc}
\hline \multirow{2}{*}{ Month } & \multicolumn{4}{c}{ Sheep $(\mathrm{n}=239)$} & \multicolumn{3}{c}{ Goat $(\mathrm{n}=196)$} \\
\cline { 2 - 9 } & LA $(\%)$ & LB $(\%)$ & LC $(\%)$ & LI (\%) & LA (\%) & LB (\%) & LC (\%) & LI (\%) \\
\hline Jan. & 14.3 & 21.4 & 35.7 & 28.6 & 10.5 & 10.5 & 47.4 & 31.6 \\
Feb & 7.1 & 15.4 & 46.2 & 30.8 & 8.6 & 14.3 & 42.9 & 34.3 \\
Mar. & 11.1 & 14.8 & 44.4 & 29.6 & ND & ND & ND & ND \\
Apr. & 15.2 & 13.7 & 43.1 & 27.4 & 9.5 & 19.1 & 47.6 & 23.8 \\
May & 23.8 & 21.4 & 30.9 & 23.8 & 11.5 & 7.6 & 46.2 & 34.6 \\
June & 15.8 & 21.1 & 36.8 & 26.3 & 17.6 & 11.8 & 44.1 & 26.5 \\
Average & 15.1 & 17.5 & 39.7 & 27.6 & 11.2 & 12.2 & 44.9 & 31.6 \\
\hline ND- Not Done & & & & & & & &
\end{tabular}

sheep were further categorized into $15.1 \%(\mathrm{n}=36)$ type A, $17.5 \%(\mathrm{n}=42)$ type $\mathrm{B}, 39.7 \%(\mathrm{n}=95)$ type $\mathrm{C}$ and $27.6 \%(n=66)$ type I. Likewise from goats, a total of 196 linguiform morphotypes were further classified as: $11.2 \%$ $(\mathrm{n}=22)$ type $\mathrm{A}, 12.2 \%(\mathrm{n}=24)$ type $\mathrm{B}, 44.9 \%(\mathrm{n}=88)$ type $\mathrm{C}$, and $31.6 \%(\mathrm{n}=62)$ type I as shown in table 5 . In both host species, the $\mathrm{C}$ type linguiform vulvar flap appeared as the most common subgroup.

\section{Discussion}

\section{Prevalence and worm burden of abomasal nematodes}

The high overall prevalence and worm load of abomasal nematodes encountered in the current study is in agreement with the results of previous studies. For example, the report of Gebrekiros (1990) supports the results of the current study and further confirms the rampant nature of abomasal nematodes. Donald (1999), Abebe and Esayas (2001), and Bersissa (2004) reported more than $90 \%$ prevalence of abomasal nematodes from the eastern part of the country. Other studies carried out on gastrointestinal nematodes of small ruminants revealed prevalence rates of $52.2 \%$ in Bale (Tesfalem, 1989), 90.2 \% in Illubabor (Bayou, 1992), $91 \%$ in Wollayita Sodo (Dereje, 1992), $91.4 \%$ in Kombolcha (Genene, 1994) for these nematodes. However, our result is not in agreement with that of El-Azazy (1995) and Wang et al. (2006). El-Azazy (1995) carried out his study in Saudi Arabia, which is a desert where hot dry climatic conditions prevail, whereas the present study was conducted in relatively wet and humid climate with variable amount of rain occurring during all months of the study period in Awassa and its surrounding in southern Ethiopia. The results of worm counts presented herein showed slightly different patterns in sheep and goats. In sheep both the overall worm count and the specific counts for the three genera of nematodes showed similar trends. Even though the variation was insignificant, higher worm loads were recorded during March and April than January and February months of the study period. These higher worm counts during March and April coincide with the short rainy season in March to May in the area. This suggests that humidity and temperature during wet months favourably supports larval development and survival of nematodes in the pasture of the study area. This finding is in line the work of Amenu (2005), El-Azazy (1995) and Fritsche et al. (1993) all of which indicated high prevalence and worm burden during months of rainy seasons. In goats, the burden decreased from January onwards and then gradually started to rise in June. This difference between sheep and goats is most probably attributed to the difference in grazing habits and physiology of the two hosts.

In both sheep and goats Haemonchus spp. with respective prevalence of $81.1 \%$ and $76.5 \%$ was identified as the most predominant abomasal nematode of the area. This suggests the widespread occurrence of Haemonchus spp. in the area and, owing to its known high pathogenic significance, it can undoubtedly contribute to subtle 
production losses, unthriftness, morbidity and mortality of small ruminants of the study area. In support of our results earlier investigators reported that Haemonchus constitutes the largest proportion of abomasal nematodes. Similar high prevalence rates of Haemonchus was observed by Bersissa (2004, 2006) in Ogaden (90.1 \%), Dereje (1992) in Wollayita Sodo (80\%), Gennene (1994) in Kombolcha (83.9\%), Getachew (1998) in Mekele (95.4\%), Githigia et al. (2001), Wang et al. (2006) and El-Azazy (1995). The result of this study revealed that there was no significant $(\mathrm{P}$ $>0.05$ ) difference in monthly infection rates of small ruminants by abomasal nematodes. This suggests the presence of infection during all months of the study period, which is in line with the observations of Bersissa (2006) and Tekelye (1987) who reported the occurrence of infection by abomasal nematodes throughout all seasons of the year.

In this study, moderate prevalence rates of $T$. axei $(47.2 \%$ and $39.4 \%)$ and Teladorsagia spp., (19.4\% and 20.5\%) in sheep and goats, respectively were recorded. Very few previous studies in Ethiopia have revealed the existence and prevalence of Teladorsagia infections in small ruminants (Amenu, 2005; Graber, 1975). The result of this study is in support of the reports made by the previous workers. Even though its prevalence was lower than that of Haemonchus and T. axei, the importance of these parasites on the health and productivity of small ruminants should not be overlooked as the immature stages of these parasites are highly pathogenic to their host (Dunn, 1978). Moreover, this nematode has developed resistance to the most commonly used anthelmintics (Scott et al., 2006) and it has become a challenge to small ruminant production.

\section{Vulvar morphology}

The study on vulvar morphology of female Haemonchus worms collected from sheep and goats revealed that the linguiform types prevailed and appeared as the most predominant morphotype in both sheep and goats. The study also showed very similar morph distribution and absence of fluctuations of the major vulvar morphs in different months of the study period both in sheep and goat hosts. This observation is inline with many other findings of Jacquiet (1995), Abebe and Esayas (2001) and Bersissa (2004).

In the current study within the linguiform morph types, the $\mathrm{C}$ type was encountered as the most predominant subtype of the study area. This finding is in contrast to the previous work of Bersissa (2004) who reported the dominance of type A in small ruminants of Ogaden region. This could be due to the difference in agro-ecological conditions or environmental factors between the two study areas. Vulvar polymorphism in Haemonchus spp. of sheep and goats is observed to be common in the study area.

Rose (1966) and Le Jambre and Whitlock (1968) indicated vulvar morphology helps to understand and know more about the biology of Haemonchus spp. and determine the type of population that occurs in sheep and goats of an area. Tod (1965) also considered that vulvar morphology is a manifestation of some genetic factors important to establish and develop in hosts. Vulvar morphology is also considered as markers of ecological adaptation to an area (Rose, 1966; Le Jambre \& Whitlock, 1968; Jacquiet, 1995). These investigators described that, based on vulvar morphology, it is possible to arrange Haemonchus spp. populations from different hosts as: the linguiform females predominate in $H$. contortus of sheep and goats, the prominently knobbed females predominate in $H$. place $i$ of cattle whereas the small knobbed and smooth females occur in equal proportions in $H$. longistipes of camels. Hence determination of the vulvar morphology of female Haemonchus spp. population of an area gives an indication as to which species is occurring.

\section{Conclusion}

This study showed that small ruminants of the study area were found to suffer from high overall and monthly prevalence of abomasal nematodes infection. In both host species abomasal nematodes (especially Haemonchus spp.) are important impediments to small ruminant production of the area. The result of the present study revealed that sheep and goats in the study area are affected by similar prevalence and pattern of abomasal nematodes and also harbor female Haemonchus worms of similar proportion of vulvar morph types. In the current study the investigation on vulvar morphology of female Haemonchus spp. in its turn disclosed the predominance of linguiform vulvar morph types in both sheep and goats. Further investigation on biology and significance of vulvar morphology of Haemonchus spp. and epidemiological studies to determine the associated losses in domestic ruminants in all seasons in different agroecology and managements need to be pursued.

\section{Acknowledgement}

The authors would like to thank the owners of the restaurants of Awassa town for providing abomasa of sheep and goats of the study.

\section{References}

ABeBE, W., Esayas, G. (2001): Survey of ovine and caprine gastrointestinal helminthosis in Eastern part of Ethiopia during dry season of the year. Revue Med. Vet., 152: $379-384$

AMENU, A. (2005): Epidemiology of gastrointestinal tract nematodiosis of small ruminant in three different agroecological zones of southern Ethiopia. MSc, Thesis FVM, AAU, Debre Zeit, Ethiopia

Bekele, M., Feseha, G., Shibiru, T. (1982): Survey of gastrointestinal tract helminthes sheep slaughtered at Addis Ababa, Ethiopia, J Agri. Sci., 4: 87 - 94

BAYOU, A. (1992): Prevalence of gastrointestinal helminths of small ruminants in Illubabor. DVM Thesis, FVM, AAU, Debre Zeit, Ethiopia

BARGER, I. A. (1982): Helminth parasites and animal pro- 
duction. Biology and control of endoparasites. Academic press, $133-135$

Bersissa, K., ABEBE, W. (2006): Abomasal Nematodes of Small Ruminants of Ogaden region, eastern Ethiopia: Prevalence, Worm Burden and Species Composition. Revue Med. Vet., 157: $27-32$

BERSISSA, K. (2004): Study on Ogaden small ruminant haemonchosis: Morphological characterization and susceptibility to Albendozale and Tetramisole. MSc Thesis, FVM, AAU, Debre Zeit, Ethiopia

CSA (Central Statistics Authority) (2004): The 2001/2002 Ethiopian Agricultural sample enumeration (EASE) Executive Summary, Addis Ababa, Ethiopia

DEREJE, G. (1992): Investigation of common gastrointestinal parasites of small ruminants in and around Wollayita Soddo. DVM Thesiss, FVM, AAU, Debre Zeit, Ethiopia DONALD, A. K. (1999): Epidemiology and seasonal dynamics of gastrointestinal helminthosis of the small ruminants of eastern and southern semi-arid Zones of Ethiopia. MSc Thesis, FVM, AAU and Freie University of Berlin DunN, A. M. (1978): Veterinary Helminthology. $2^{\text {nd }}$ Ed., Butter and tanner LTD, London, Great Britain, 88 Devendera, C., Mcleroy, G. B. (1982): Goat and sheep production in tropics. Singapore, ELBI with Longman, 1 7

El-AZAZY, O. M. E. (1995): Seasonal changes and inhibitted development of the abomasal nematodes of sheep and goats in Saudi Arabia. Vet. Parasitol., 58: 91 - 98

Fritsche, T., Kaufmann, J., Pfister, K. (1993): Parasite spectrum and seasonal epidemiology of gastrointestinal nematodes of small ruminants in the Gambia. Vet. Parasitol., 49: $271-283$

GEBREKIROS, A. (1990): The study of ovine helminthiasis in Awassa and the effect of control with Nilzana. MSc Thesis, AAU, Ethiopia

GENENE, R. (1994): Study on prevalence of ovine gastrointestinal helminthosis in and around Kombolcha, DVM Thesis, FVM, AAU, Debre Zeit, Ethiopia

Getachew, G. (1998): Prevalence of bovine and caprine gastrointestinal helmiths in Mekele and its surrounding, DVM Thesis, FVM, AAU, Debre Zeit, Ethiopia

Githigia, S. M., Thamsborg, S. M., Munyua, W. K., MiANGI, N. (2001): Impact of gastrointestinal helminths on production in goats in Kenya. Small. Rumin. Res., 42: $21-$ 29

GRABER, M. (1975): Helminthes and helminthosis of domestic and wild animals in Ethiopia. Rev. d'Elev. Med. Vet. Pays Trop., 2 (6)

Hansen, J., Perry, B. (1994): Epidemiology, Diagnosis and control of helminth parasites of ruminants. A hand book, ILRAD, Nairobi, Kenya, 13 - 17

JaCquiet, P., Humbert, J. F., Comes, A. M., CABARet, J. THIAM, A., CHEIKH, D. (1995): Ecological, morphological, and genetic characterization of sympatric Haemonchus spp. of parasites of domestic ruminants in Mauritania. Parasitol., 110: 483 - 492

JAHNKE, H. E. (1992): Livestock production system and live stock development in topical Africa. Keler wissench hafts verlag uauk, Kill, Germany, 253

KRECEK, R. C., WALLER, P. J. (2006): Towards the implementation of the "basket of options" approach to helminth parasite control of livestock: emphasis on the tropics/ subtropics. Vet. Parasitol., 139: 270 - 282

LE JAmBre, L. F., Whitlock, J. H. (1968): Seasonal fluctuation in linguform morphs of Haemonchus contortus cayugenstis. J. Parasitol., 54: $827-830$

MAFF (Ministry of Agriculture, Fisheries and Food). (1977): Manual of Veterinary Parasitological Laboratory Techniques. Tech. Bull. No., 18: Her majesty's Stationery office, London $1-5$

Mulugeta, H. S., Getachew, T., Taffesse, M., GetaChew, W., M., Kinfe, G., Teshome, Y. (1989): The significance of helminth in livestock production. The $2^{\text {nd }}$ national livestock improvement conference, May $24-26$, 1989, IAR, Addis Ababa, Ethiopia, 49 - 53

Rose, J. H. (1966): The Vulval flap formula of Haemonchus contortus from sheep in South east England. Res. Vet. Sci., 7: $480-483$

ScotT, P. R., SARgison, N. D., WiLson, D. T. (2006): The potential for improving welfare standards and productivity in United Kingdom sheep flocks using veterinary flock health plans. Vet. Journal, (in press)

Teklye, B., Mukassa, E., Scholtens, R. C. (1987): Seasonal changes in nematodes faecal egg counts in Ethiopian high lands, ILCA, Bulletin No 29, Addis Ababa, Ethiopia, $10-12$

TESFALEM, T. (1989): Prevalence of gastrointestinal helminthes of small ruminants in Mendeyo province of Bale administrative region, DVM Thesis, FVM, AAU, Debre Zeit, Ethiopia.

TOD, M. E. (1965): On the Morphology of Haemonchus contortus (Rudolphi 1803) Cobb (Nematoda: Trichostrongylidae) in sheep and cattle. Aust. J. Zool., 13: $773-81$

WANG, C. R., QIU, J. H., ZHU, X. Q., HAN, X. H., Ni H. B., ZhaO, J. P., ZhOU, Q. M., Zhang, H. W., Lun, Z. R. (2006): Survey of helminths in adult sheep in Heilongjiang province, People's Republic of China. Vet. Parasitol., 140: $378-382$ 